\title{
Nano Technological Drug Release Approaches for the Treatment of Eye Diseases: Myth, Reality or Challenge?
}

\author{
María Lina Formica ${ }^{1,2}$, Juan Pablo Real ${ }^{1,2}$, Daniel Allemandii ${ }^{1,2}$ and Y Santiago Palma ${ }^{1,2 *}$ \\ ${ }^{1}$ Department of Pharmaceutical Sciences, National University of Cordoba, Argentina \\ ${ }^{2}$ Research and Development Unit in Pharmaceutical Technology, Argentina
}

Submission: February 09, 2018; Published: February 28, 2018

*Corresponding author: Y Santiago Palma, Haya de la Torre Medina Allende, Ciudad Universitaria, X5000HUA Córdoba, Argentina, E-mail: sdpalma@fcq.unc.edu.ar.

\section{Editorial}

Drug ophthalmologic administration is a great challenge for pharmaceutical technology due to ocular barriers limit drugs access to action site. The common routes of administration are topical instillation or sub conjunctival injection for the treatment of anterior segment of eye; while, for the administration of drugs to the posterior segment, the most common routes include systemic dosing, periocular or intravitreal injections and, to a lesser extent, topical instillation. More than $90 \%$ of ophthalmic formulations are marketed in the form of solutions, suspensions or ointments beginning topical administration are the most accepted strategy for most drugs due to its noninvasive condition. The drug administration by this route has two different purposes: the superficial treatment of eye in diseases such as infections (conjunctivitis, blepharitis, keratitis) and intraocular treatment for diseases as glaucoma or uveitis which drug should permeate through the cornea or other tissues.

However, bioavailability of instilled compound is low due ocular elimination mechanisms and barriers hinder drug access. After instillation of eye drops, less than $5 \%$ of the druggoes through the cornea and reaching intraocular tissues while most of the part of it is absorbed systemically thorough conjunctiva and nasolacrimal duct. At same time, systemically administered drugs have poor access to aqueous and vitreous humourepithelium. In this way, frequently, intravitreal injection is the most appropriate alternative to achieve high drug concentrations in posterior segment by injecting drugs to all layers of the ocular globe. The vitreous humour is a gelatinous, cell-free structure that is able to retain molecules and envelop them in structures of the corneas, such as the ciliary body or retinal pigment. However, it should be noted this method is very invasive, poorly accepted by the patient and, for most of the disorders of the retina, a significant number of applications are necessary.
In addition, these frequent injections may have side effects such as increased risk of developing cataracts, intraocular haemorrhages, retinal detachment, endophthalmitis and uveitis. In recent years, there has been an increase in the development of systems or devices that allow a drug to be released in a controlled manner or to target a specific region of the organism. Thus, research on modified-release systems has undergone important development, supported by the pharmacokinetic knowledge of the drugs and the great advances in the production of new materials that can be used as modulators of the release [1] .Different therapeutic aspects raise the need to generate research and development ( $\mathrm{R} \& \mathrm{D}$ ) projects aimed at generating knowledge and obtaining innovative products that cover this type of health needs.

In that sense in 2002, the World Health Organization published an article in the prestigious journal Nature Genetics which emphasizes the need to prioritize the development of certain biotechnologies in developing or emerging countries. In a ranking (top ten) drug delivery systems were positioned in third place as fundamental tools for improving the health of the population [2].In this sense, different systems such as implants (biodegradable and non-biodegradable) and several based-nanotechnology strategies have developed to overcome biological barriers and to improve ocular drug therapy. In 1985, Wood et al. demonstrated for the first time the intrinsic ability of nanoparticles to adhere to the ocular surface and interact with the epithelium and therefore multiplied efforts to use nanotechnology tools for the improvement of ophthalmologic pharmacotherapy [3].

It has been demonstrated that nanoparticles can enhance the solubility of hydrophobic drugs in aqueous solution allow delivery of therapeutic agents by topical or intravitrealroutes and minimize ocular irritation due to small size. Moreover, 
nanoparticles properties as muco adhesiveness, protection of active molecule and biodegradability favour the therapeutic effect. Several nano carriers were developed for treatment of eye infectious diseases, ocular inflammation, glaucoma and immune mediated ocular surface symptoms. In vivo studies have showed increase of residence time, enhance of corneal permeability and better release profile after topical administration of nanoparticles loaded with antibiotics, antifungal, corticosteroids, immunosuppressant or non steroidal anti-inflammatory drugs [4].

Beyond relatively simple applications such as the transport of soluble drugs that due to their nature do not permeate the cornea or other structures, attention has been focused on more important challenges and greater impact such as the administration of drugs for pathologies of the posterior segment. In many of these diseases, local application of drug to vitreous at a therapeutic concentration is required. Taking into account the increase of pathologies of the posterior segment, it is necessary to design new technological platforms that allow the drugs to reach intraocular tissues and the vitreous humour from the outside of the eye as to improve performance of injections. The primary target is to maintain the therapeutic levels of a drug in the vitreous for a longer period of time than a single intravitreal injection constituting a substantial improvement in the quality of life of many patients.

In this sense, nanoparticles have showed sustained drug release over an extended period of time reduces the need for frequent intravitreal injections and the risk of associated side effects. Additionally, they can remain in the eye for several months after administration maintaining therapeutic concentrations at the target site over longer periods. In this sense, polymeric nanoparticles have demonstrated higher residence time or sustained release after intravitreal injection in animal models. Dexamethasone loaded poly(lactic-co-glycolic acid) nanoparticles, ganciclovir-loaded albumin nanoparticles and triamcinolone acetonidepolylactic acid nanoparticles, are included as examples [5-7].

Furthermore, liposome's have been studied as delivery system to posterior segment of the eye due to lipid nature would cross barriers. Many liposomal systems loaded with anti-inflammatory, antibiotics and antiviral drugs, have been proposed for posterior eye delivery by intravitreal route. Visudyne is the only marked liposomal formulation contains verteporfin used for the treatment of neovascularisation in age macular degeneration. Finally, developments of nanocarriers for antibody delivery are other important improve such as bevacizumab-loaded nanoparticles for neovascularisation treatment. Bevacizumab achieved sustained release after intravitreal administration when it was incorporated in liposome's, polymeric nanoparticles including poly (lactic-coglycolic acid), polylactic acidor albumin) and also, encased into hydro gels or thermo sensible gels [8-10].
Obtaining nano carriers capable of transporting antibodies that allow a longer residence time of drug in the vitreous, thus decreasing the frequency of intravitreal injection would be of special utility to improve adherence in chronic diseases such as Age-related Macular Degeneration (AMD) or Diabetic Retinopathy. In the treatment of these diseases, none of the drugs used (anti-VEGF drugs such as Ranibizumab or Bevacizumab) resolves the underlying cause of them, only temporarily eliminates the excessive presence of VEGF in the affected eye. When the drug, due to pharmacokinetic issues, is no longer present at the site of action, VEGF will begin to accumulate until it again reaches excess [11].This leads to patients receiving injections with a high frequency, something that in practice usually does not occur. The consequence is clear differences in the effectiveness achieved in clinical practice compared to that reported in clinical trials $[12,13]$.

In this sense, the achievement of nanoparticles able to release sustained anti-VEGF drugs, thus prolonging the VEGF blocking time and therefore the need for re injections, would improve the adherence of these treatments with the consequent improvement of the effectiveness and quality of life of the patients.

In this way, it be noted that nano carriers systems have great potential as strategies for drug delivery to diseases of the posterior ocular segment. Effectiveness, loading capacity and stability of this are the main aspects described. However, it is necessary to regard that possible toxicity of nano carriers and its structural components not have extensively studied. The nano carrier development should be addressed to achieve formulations that in the future are applicable in patients. For this, it is important to make a joint interdisciplinary work among professionals of clinical, chemistry and pharmaceutical technology fields.

\section{References}

1. Liu D, Yang F, Xiong F, Gu N (2016) The smart drug delivery system and its clinical potential. Theranostics 6(9): 1306-1323.

2. Daar AS, Thorsteinsdottir H, Martin DK, Smith AC, Nast S (2002) Top ten biotechnologies for improving health in developing countries. Nature Genetics 32(2): 229-232.

3. Wood R W Li Vincet H K, Kreuter J, Robinson JR (1985) Ocular disposition of poly-hexyl-2-cyano [3-14C]acrylate nanoparticles in the albino rabbit. International Journal of Pharmaceutics 23(2): 175-183.

4. Battaglia L, Serpe L, Foglietta F, Muntoni E, Gallarate M, et al. (2016) Application of lipid nanoparticles to ocular drug delivery. Expert Opinion on Drug Delivery 13(12): 1743-1757.

5. Kadam RS, Tyagi P, Edelhauser H F, Kompella UB (2012) Influence of choroidal neovascularization and biodegradable polymeric particle size on transscleral sustained delivery of triamcinolone acetonide. International Journal of Pharmaceutics 434(1-2): 140-147.

6. Merodio M, Irache JM, Valamanesh F, Mirshahi M (2002) Ocular disposition and tolerance of ganciclovir-loaded albumin nanoparticles after intravitreal injection in rats. Biomaterials 23(7): 1587-1594. 
7. Zhang L, Li Y, Zhang C, Wang Y, Song C, et al. (2009) Pharmacokinetics and tolerance study of intravitreal injection of dexamethasone-loaded nanoparticles in rabbits. International Journal of Nanomedicine.

8. Abrishami M, Zarei Ghanavati S, Soroush D, Rouhbakhsh M, Jaafari M $\mathrm{R}$, et al. (2009) Preparation, characterization, and in vivo evaluation of nanoliposomes-encapsulated bevacizumab (avastin) for intravitreal administration. Retina (Philadelphia Pa) 29(5): 699-703.

9. Varshochian R, Riazi Esfahani M, Jeddi Tehrani M, Mahmoudi AR, Aghazadeh S, et al. (2015) Albuminated PLGA nanoparticles containing bevacizumab intended for ocular neovascularization treatment. Journal of Biomedical Materials Research Part A 103(10): 3148-3156.

10. Yandrapu SK, Upadhyay AK, Petrash JM, Kompella UB (2013) Nanoparticles in porous microparticles prepared by supercritical

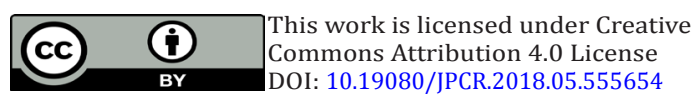

infusion and pressure quench technology for sustained delivery of bevacizumab. Molecular Pharmaceutics 10(12): 4676-4686.

11. Zhang Y, Yao Z, Kaila N, Kuebler P, Visich J, et al. (2014) Pharmacokinetics of ranibizumab after intravitreal administration in patients with retinal vein occlusion or diabetic macular edema. Ophthalmology 121(11): 2237-2246.

12. Michael W Stewart (2015) Individualized Treatment of Neovascular Age-Related Macular Degeneration: What are Patients Gaining? Or Losing? J Clin Med 4: 1079-1101.

13. Real JP, Luna JD, Urrets Zavalia JA, De Santis MO, Palma SD, et al. (2013) Accessibility as a conditioning factor in treatment for exudative agerelated macular degeneration. Eur J Ophthalmol 23(6): 857-864.

\section{Your next submission with Juniper Publishers will reach you the below assets}

- Quality Editorial service

- Swift Peer Review

- Reprints availability

- E-prints Service

- Manuscript Podcast for convenient understanding

- Global attainment for your research

- Manuscript accessibility in different formats ( Pdf, E-pub, Full Text, Audio)

- Unceasing customer service

Track the below URL for one-step submission https://juniperpublishers.com/online-submission.php 